\title{
Reactivity of neonicotinoid insecticides with carbonate radicals
}

\section{María Laura Dell'Arciprete ${ }^{a}$, Juán M. Soler ${ }^{b}$, Lucas Santos-Juanes ${ }^{c}$, Antonio Arques $^{b}$, Daniel O. Mártire ${ }^{a}$, Jorge P. Furlong ${ }^{d}$, Mónica C. Gonzalez ${ }^{a, *}$}

${ }^{a}$ Instituto de Investigaciones Fisicoquímicas Teóricas y Aplicadas (INIFTA), Facultad de Ciencias Exactas, Universidad Nacional de La Plata, Casilla de Correo 16, Sucursal 4, (1900) La Plata, Argentina

${ }^{\mathrm{b}}$ Grupo de Procesos de Oxidación Avanzada, Departamento de Ingeniería Textil y Papelera, Universidad Politécnica de Valencia, Campus de Alcoy, Plaza Ferrandiz y Carbonell s/n, 03801 Alcoy, Spain

${ }^{c}$ CIESOL, Joint Centre of the University of Almería-CIEMAT, Ctra de Sacramento s/n, 04120 Almería, Spain

${ }^{d}$ LADECOR, Departamento de Química, Facultad de Ciencias Exactas, Universidad Nacional de La Plata, Casilla de Correo 16, Sucursal, 1900 La Plata, Argentina

\section{A R T I C L E I N F O}

\section{Article history:}

Received 1 November 2011

Received in revised form

14 March 2012

Accepted 24 March 2012

Available online 5 April 2012

Keywords:

Carbonate radicals

Neonicotinoid indecticides

Imidacloprid

Thiacloprid

Acetamiprid

$\alpha$-Aminoalkyl radical

\begin{abstract}
A B S T R A C T
The reaction of three chloronicotinoid insecticides, namely Imidacloprid (IMD), Thiacloprid (THIA) and Acetamiprid (ACT), with carbonate radicals $\left(\mathrm{CO}_{3}^{-}\right)$was investigated. The second order rate constants $(4 \pm 1) \times 10^{6},(2.8 \pm 0.5) \times 10^{5}$, and $(1.5 \pm 1) \times 10^{5} \mathrm{M}^{-1} \mathrm{~s}^{-1}$ were determined for IMD, THIA and ACT, respectively. The absorption spectra of the organic intermediates formed after $\mathrm{CO}_{3}^{-}$attack to IMD is in line with those reported for $\alpha$-aminoalkyl radicals. A reaction mechanism involving an initial charge transfer from the amidine nitrogen of the insecticides to $\mathrm{CO}_{3}^{--}$is proposed and further supported by the identified reaction products. The pyridine moiety of the insecticides remains unaffected until nicotinic acid is formed. $\mathrm{CO}_{3}^{--}$radical reactivity towards IMD, ACT, and THIA is low compared to that of $\mathrm{HO}^{\bullet}$ radicals, excited triplet states, and ${ }^{1} \mathrm{O}_{2}$, and is therefore little effective in depleting neonicotinoid insecticides.
\end{abstract}

() 2012 Elsevier Ltd. All rights reserved.

\section{Introduction}

Carbonate radical $\left(\mathrm{CO}_{3}^{-}\right)$is a selective one-electron oxidant, $\mathrm{E}^{\mathrm{O}}$ $\left(\mathrm{CO}_{3}^{-} / \mathrm{CO}_{3}^{2-}\right)=1.78 \mathrm{~V}$ us. NHE (Wu and Linden, 2010), capable of initiating the oxidation of many organic compounds. Carbonate radical reactivity is high for electron-rich N-containing chemicals such as heterocycles, fenuron, carbendazim and phenylurea herbicides (Busset et al., 2007; Mazellier et al., 2007). It is also reactive with sulphur-containing compounds such as thioanisole, dibenzothiophene, fenthion, and
S-triazine (Canonica et al., 2005; Mazellier et al., 2002; Huang and Mabury, 2000a) with reaction rate constants $k$ ranging from $10^{6}$ to $10^{8} \mathrm{M}^{-1} \mathrm{~s}^{-1}$. Aliphatic alcohols are among the least reactive with $k$ in the range from $10^{3}$ to $10^{5} \mathrm{M}^{-1} \mathrm{~s}^{-1}$ (Clifton and Huie, 1993; Neta et al., 1988).

Carbonate radicals in natural waters are mainly formed by the reactions of carbonate/bicarbonate ions with either hydroxyl radicals or aromatic-ketones triplet excited states as those contained in dissolved organic matter, DOM (Canonica et al., 2005; Huang and Mabury, 2000b; Lam et al., 2003;

\footnotetext{
* Corresponding author. Tel.: +54 221425 7430; fax: +54 2214254642 .

E-mail addresses: gonzalez@inifta.unlp.edu.ar, mcgonzalez.quim@gmail.com (M.C. Gonzalez). 0043-1354/\$ - see front matter @ 2012 Elsevier Ltd. All rights reserved. doi:10.1016/j.watres.2012.03.051
} 
Vione et al., 2009a; Wu and Linden, 2010). The transformation of the highly reactive $\mathrm{HO}^{\circ}$ to $\mathrm{CO}_{3}^{--}$radicals in surface waters decreases the environmental disappearance rate of electronpoor compounds which are unreactive towards $\mathrm{CO}_{3}^{--}$. On the other hand, electron-rich systems might show an enhanced phototransformation due to the presence of carbonate ions (Vione et al., 2009b). Carbonate radicals steady-state concentration of $10^{-13}-10^{-15} \mathrm{M}$ found in natural waters supports the increasing evidence reported in the literature for their important role in the self-cleaning of the hydrosphere basins. Mazellier and coworkers suggested that the degradation of the fungicide carbendazim by $\mathrm{CO}_{3}^{-}$in natural waters and carbonate-contaminated effluents cannot be neglected compared to that initiated by hydroxyl radicals (Mazellier et al., 2002). Also, Huang and Mabury confirmed that $\mathrm{CO}_{3}^{-}$ contribute to the photodegradation of sulphur-containing xenobiotics in natural and artificial waters (Huang and Mabury, 2000a). Despite the long regarded importance of $\mathrm{CO}_{3}^{--}$in the water environment, studies discussing its reaction mechanisms towards organic contaminants are scarce.

Neonicotinoid insecticides are among the most important commercial insecticides used worldwide owing to their high insecticidal activity, broad insecticidal spectra, good systemic properties, and suitable field stability (Zabar et al., 2011). Their photodegradation in aquatic media (Moza et al., 1998; Redlich et al., 2007; Wamhoff and Schneider, 1999), and in advanced oxidation procedures technologies such as solar photo-Fenton and heterogeneous photocatalysis under UV-irradiated $\mathrm{TiO}_{2}$ have been reported in the literature (Malato et al., 2001; Cernigoj et al., 2007).

In the last years, the reactivity, mechanisms, and primary degradation products of Imidacloprid (IMD), Thiacloprid (THIA) and Acetamiprid (ACT) (Scheme 1) with hydroxyl radical (Dell'Arciprete et al., 2009), singlet oxygen, and excited triplet states have been investigated (Dell'Arciprete et al., 2010). Here, kinetic and mechanistic studies on $\mathrm{CO}_{3}^{--}$oxidation of the insecticides IMD, THIA and ACT are reported, and the importance of these reactions in the self cleansing of the insecticides contained in natural waters to safe levels (of the order of 67 ng/L for IMD (Tennekes and Sánchez-Bayo, 2011)) is discussed.

\section{Materials and methods}

\subsection{Chemicals}

Imidacloprid, Acetamiprid, and Thiacloprid were purchased from Aldrich and used as received. Sodium peroxodisulphate, $\mathrm{NaOH}$, and $\mathrm{HClO}_{4}$ from Merck, were used without further purification. Demineralized water used was of Milli-Q quality ( $>18 \mathrm{M} \Omega \mathrm{cm},<20 \mathrm{ppb}$ of organic carbon). The $\mathrm{pH}$ of the solutions was adjusted to $7.7 \pm 0.5$ with a $\mathrm{HCO}_{3}^{-} / \mathrm{H}_{2} \mathrm{CO}_{3}$ buffer by addition of $\mathrm{HClO}_{4}$ to a $1 \mathrm{M} \mathrm{KHCO}_{3}$ solution and measured with a Consort pH-meter model C832.

Carbonate radicals are generated in situ by reaction of bi/ carbonate ions with sulphate radicals. Photolysis of aqueous solutions of $\mathrm{S}_{2} \mathrm{O}_{8}^{2-}$ with excitation wavelengths $\lambda_{\text {exc }}<300 \mathrm{~nm}$, reaction (1) in Table 1 , is a clean source of sulphate radical ions, $\mathrm{SO}_{4}^{--}$. The latter radicals are scavenged by excess $\mathrm{KHCO}_{3}$, reaction (2), with rate constant $k_{2}=3 \times 10^{6} \mathrm{M}^{-1} \mathrm{~s}^{-1}$ (Huie et al., 1991). Carbonate radicals are expected to be the main oxidizing species in solution if $\left[\mathrm{HCO}_{3}^{-}\right] \sim 1 \mathrm{M}$ and [insecticides] $<10^{-4} \mathrm{M}$. This condition was kept in timeresolved experiments performed to determine the rate constants of the reactions of $\mathrm{CO}_{3}^{-}$radicals with the insecticides.

\subsection{Time-resolved experiments}

Flash photolysis experiments were carried out using a conventional flash apparatus, Xenon Co. model 720C with modified optics and electronics. A more detailed description of the technique can be found elsewhere (Bensasson et al., 1983). Briefly, two collinear quartz Xenon high-intensity pulsed flash tubes, Xenon Corp. P/N 890-1128 (FWHM $\leq 20 \mu \mathrm{s}$ ), with a continuous spectral distribution ranging from 200 to $600 \mathrm{~nm}$ and maximum around $450 \mathrm{~nm}$ were used. The analysis source was a high pressure mercury lamp (Osram HBO-100 W). The optical path length of the $1 \mathrm{~cm}$ internal diameter quartz sample cell was $10 \mathrm{~cm}$. The monochromator collecting the analysis beam (Bausch \& Lomb, high-intensity) was directly coupled to a photomultiplier (RCA 1P28), which output was fed into a digital oscilloscope (HP 54600B). Digital data were stored in a personal computer. The emission of the flash lamps was filtered with an aqueous concentrated solution of the corresponding insecticide in order to avoid photolysis of the substrate. The temperature $\left(25 \pm 3^{\circ} \mathrm{C}\right)$ was measured inside the reaction cell with a calibrated Digital Celsius Pt-100 $\Omega$ thermometer. Freshly prepared solutions were used in order to avoid possible thermal reactions of peroxodisulphate with the substrates.

\subsection{Chemical analyses}

Samples for product detection were obtained from $254 \mathrm{~nm}$ -irradiated oxygen-saturated solutions containing $80 \mathrm{mg} / \mathrm{L}$ of the insecticides, $0.025 \mathrm{M}$ of $\mathrm{Na}_{2} \mathrm{~S}_{2} \mathrm{O}_{8}$ and $1 \mathrm{M}$ of $\mathrm{KHCO}_{3}$. To that purpose, a $1 \mathrm{~L}$ capacity cylindrical glass reactor continuously bubbled with $\mathrm{O}_{2}$ was used. The reactor was equipped with an<smiles>C/C(=N/C#N)N(C)Cc1ccc(Cl)nc1</smiles>

ACT<smiles>N#C/N=C1\SCCN1Cc1ccc(Cl)nc1</smiles>

THIA<smiles>O=[N+]([O-])N=C1NCCN1Cc1ccc(Cl)nc1</smiles>

IMD 


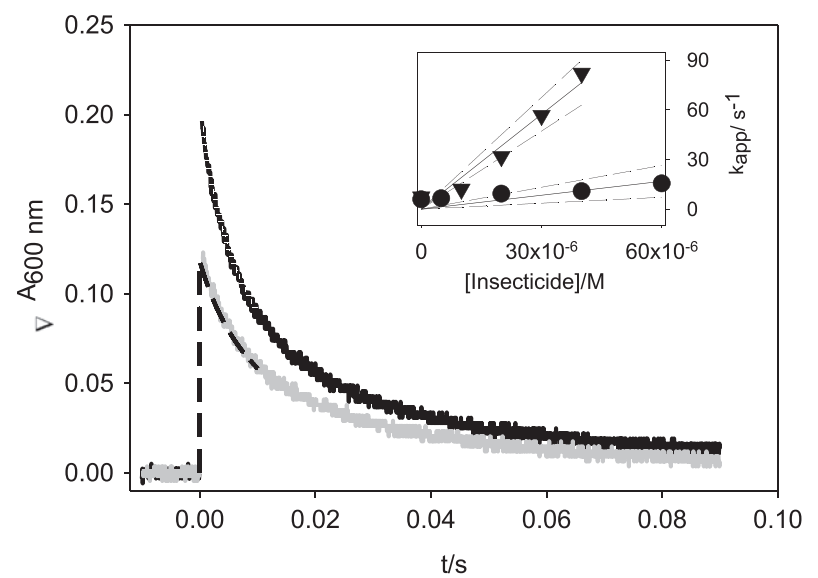

Fig. 1 - Absorbance traces at $600 \mathrm{~nm}$ obtained in experiments with solutions containing $0.025 \mathrm{M} \mathrm{Na}_{2} \mathrm{~S}_{2} \mathrm{O}_{8}$ and $1 \mathrm{M} \mathrm{KHCO}_{3}$ in the presence (grey curve) and absence (black curve) of $1 \times 10^{-5} \mathrm{M}$ of IMD. The dotted white line stands for the computer simulation obtained for $\mathrm{CO}_{3}^{--}$ profiles under the experiment conditions in the absence of IMD (see text). The dashed black line stands for the computer simulation obtained for $\mathrm{CO}_{3}^{-}$profiles under the experiment conditions in the presence of $1 \times 10^{-5} \mathrm{M}$ IMD (see text). Inset: Apparent rate constant as a function of insecticide concentration for ( $\nabla)$ THIA and (0) ACT. The dashed curves show the confidence interval at $95 \%$.

The rate constant for the bimolecular recombination of $\mathrm{CO}_{3}^{--}$radicals, reaction (3) in Table 1 , may be obtained from the relation $c(\lambda)=2 k_{3} / \varepsilon$ l. Taking $c(\lambda)$ values obtained from the fitting of the traces at $600 \mathrm{~nm}$ to Eq. (1) and considering $\varepsilon_{600}\left(\mathrm{CO}_{3}^{--}\right)=2000 \pm 100 \mathrm{M}^{-1} \mathrm{~cm}^{-1}$, (Zuo et al., 1999) it results that $2 k_{3}=(1.1 \pm 0.1) \times 10^{7} \mathrm{M}^{-1} \mathrm{~s}^{-1}$ for a reactive mixture of 1.08 ionic strength. The obtained value agrees with that reported for $k_{3}$ in solution of ionic strength $=1.5$ (Czapski et al., 1994;
Zuo et al., 1999). Values of $k_{\text {app }}$ obtained from the fitting to Eq. (1) are independent of the detection wavelength $\lambda$ and linearly increase with the analytical concentration of the insecticide, [Ins $]_{0}$, as shown in Fig. 1 inset for THIA and ACT. The slope of these straight lines yield the bimolecular rate constants $k_{4}$ for reaction (4), depicted in Table 1.

The reaction rates obtained for the chloronicotinoid insecticides are on the same order of those reported for the herbicides atrazine (1-chloro-3-ethylamine-5-isopropylamine-2,4,6-tryacine) (Huang and Mabury, 2000a) and fenuron (1,1-dimetyl-3-phenylurea) (Mazellier et al., 2007), and the fungicide carbendazim (metylbenzimidazol-2-ylcarbamate) (Mazellier et al., 2002).

\subsection{Stable products identification}

Insecticide degradation products were identified after 15 and 30 min continuous UV irradiation (254 nm) of oxygensaturated aqueous solutions of $\mathrm{pH} 7.7$ containing $80 \mathrm{mg} / \mathrm{L}$ of the insecticides, $0.025 \mathrm{M}$ of $\mathrm{Na}_{2} \mathrm{~S}_{2} \mathrm{O}_{8}$ and $1 \mathrm{M}$ of $\mathrm{KHCO}_{3}$. Table 2 shows the identified products and their mass spectrum (MS).

\subsection{Computer simulation of the experiments}

Since $\mathrm{CO}_{3}^{--}$radicals are formed from the reaction of the strong oxidizing $\mathrm{SO}_{4}^{-}$radicals with excess carbonate ions, there was concern on the possibility that the oxidation of the insecticides could also be initiated by $\mathrm{SO}_{4}^{--}$, reaction (5), and that the organic radicals formed in the reaction system could further contribute to the depletion of $\mathrm{CO}_{3}^{-}$. To probe that such reactions were of little significance under the experimental conditions used for the determination of the rate constants, a computer program was built to simulate the experimental absorbance profiles of $\mathrm{SO}_{4}^{--}$and $\mathrm{CO}_{3}^{--}$. To this purpose, reactions (1)-(5) along with the reactions of $\mathrm{SO}_{4}^{--}$with water and peroxodisulphate ions (reactions (6) and (7), respectively), and $\mathrm{SO}_{4}^{-}$bimolecular recombination (reaction (8)), were taken into account. The reaction rate constants used are those depicted

Table 2 - Observed degradation products formed after the reaction of $\mathrm{CO}_{3}^{-}$and/or $\mathrm{SO}_{4}^{-}$radicals with the insecticides, see text. GC retention times, $R_{t}$, and MS mass to charge ratios $m / z$, are given, together with assigned products.

\begin{tabular}{|c|c|c|c|}
\hline \multirow[t]{2}{*}{ Insecticide } & 15 min irradiation & 30 min irradiation & \multirow[t]{2}{*}{ Product assignment } \\
\hline & $m / z, R_{t}$ in $\min$ & $m / z, R_{t}$ in $\min$ & \\
\hline IMD & $\begin{array}{l}140,112,85,76 R_{\mathrm{t}}=11.5 \\
264,153,126 R_{\mathrm{t}}=37.5\end{array}$ & & 6-chloronicotinic aldehyde, compound 1 in Scheme 2 \\
\hline THIA & $\begin{array}{l}140,112,85,76 R_{\mathrm{t}}=11.5 \\
264,153,126 R_{\mathrm{t}}=37.5\end{array}$ & $\begin{array}{l}140,112,85,76 R_{\mathrm{t}}=11.5 \\
264,153,126 R_{\mathrm{t}}=37.5\end{array}$ & $\begin{array}{l}\text { compound 2. See S.I. } 2 . \\
\text { 6-chloronicotinic aldehyde, compound } 1 .\end{array}$ \\
\hline ACT & $\begin{array}{l}97,82,67 R_{t}=18.5 \\
140,112,85,76 R_{t}=11.5\end{array}$ & & $\begin{array}{l}\text {, compound 2. See S.I. } 2 \\
\mathrm{~N}^{\prime} \text {-cyano-N-methyl acetamidine, compound 3, Sch. } 4 . \\
\text { 6-chloronicotinic aldehyde, compound } 1 .\end{array}$ \\
\hline
\end{tabular}


in Table 1. The flash emission was considered a delta function producing $\mathrm{SO}_{4}^{--}$radicals. An initial $\mathrm{SO}_{4}^{--}$radical concentration of $10^{-5} \mathrm{M}$ was taken as an input parameter as estimated from experiments under identical conditions but in the absence of carbonate ions taking $\varepsilon^{450}\left(\mathrm{SO}_{4}^{--}\right)=1600 \mathrm{M}^{-1} \mathrm{~cm}^{-1}$ (McElroy, 1990). Only for IMD, a $20-30 \%$ inner filter effect due to the insecticide absorption of the polychromatic light emitted by the flash lamps was taken into account (see S.I Fig. 1). Simulated concentration profiles for these transients were converted into the corresponding absorbance curves and compared to the experimental data to fit the set of experiments. A good agreement between experimental and simulated profiles for $\mathrm{CO}_{3}^{--}$traces was observed in the absence and presence of the insecticides, as depicted for IMD by the dotted and dashed lines in Fig. 1. Therefore, experimental $\mathrm{CO}_{3}^{--}$decay rates give confident information on the $k_{4}$ values depicted in Table 1.

Since [insecticides] $>10^{-4} \mathrm{M}$ were used in the continuous irradiation experiments of Section 3.2 to determine the products of reaction (4), the generation of detectable concentrations of products due to the reaction between the insecticides and $\mathrm{SO}_{4}^{--}$radicals cannot be neglected. In fact, under the experimental conditions used, the relations $k_{5, \mathrm{THIA}} \times[\mathrm{THIA}] /$ $k_{2} \times\left[\mathrm{HCO}_{3}^{-}\right]>0.05$ and $k_{5, \mathrm{ACT}} \times[\mathrm{ACT}] / k_{2} \times\left[\mathrm{HCO}_{3}^{-}\right]>0.05$ apply, strongly suggesting that the competition of THIA (and that of ACT) with $\mathrm{HCO}_{3}^{-}$anions for $\mathrm{SO}_{4}^{--}$radicals is not negligible. To evaluate the magnitude of this contribution, computer simulations were also performed setting as initial parameters the reactant concentrations used in these experiments and considering continuous irradiation conditions under airsaturation. To this purpose, $\mathrm{SO}_{4}^{--}$radicals were assumed to be formed at a rate of $5 \times 10^{-6} \mathrm{M} \mathrm{s}^{-1}$ as expected for the irradiation with a $15 \mathrm{~W}$ low-pressure $\mathrm{Hg}$ lamp of a $0.025 \mathrm{M}$ $\mathrm{S}_{2} \mathrm{O}_{8}^{-2}$ solution $\left(\mathrm{S}_{2} \mathrm{O}_{8}^{-2}\right.$ photodissociation quantum yield in the range from 0.5 to 0.7, Criquet and Karpel Vel Leitner, 2009) contained in a $2.5 \mathrm{~cm}$ optical pathway reactor. The participation of hydroxyl radicals in the overall mechanism is of little significance since, under our experimental conditions, sulphate radical scavenging by water (reaction (6)) is a hundred times slower than reaction (2). Inclusion of the reactions of hydroxyl radicals with $\mathrm{CO}_{3}^{2-} / \mathrm{HCO}_{3}^{-}$(Ross et al., 1998) and with the insecticides (Table 3 ) in the simulations does not modify the distribution of products. The stacked bar plot in S.I. 3, shows the percentage of products due to reactions with carbonate and sulphate radicals (reactions (4) and (5), respectively) formed after the quantitative depletion of the insecticides, as retrieved from the computer simulations. From the comparison of the bars it results that the generation of products from reaction (5) is of little significance only for IMD. However, almost 60 and $70 \%$ contribution of the products of reaction (5) is expected for ACT and THIA, respectively.

\subsection{Organic radical intermediates}

To obtain information on the nature of the organic transients formed after reaction (4), flash photolysis of argon- or airsaturated solutions of $\mathrm{pH} 7.7$ containing $0.025 \mathrm{M} \mathrm{S}_{2} \mathrm{O}_{8}^{2-}, 1 \mathrm{M}$ $\mathrm{HCO}_{3}^{-}$and $2 \times 10^{-4} \mathrm{M}$ of the insecticides were performed. For each insecticide, several decay profiles were obtained at different wavelengths in the range from 300 to $650 \mathrm{~nm}$. A bilinear regression analysis was applied to each absorbance matrix to gain information on the minimum number of transients formed.

\subsubsection{IMD radical intermediates}

For experiments with IMD, the bilinear analysis indicates that the data obtained may be described by two transient species with spectra and decay profiles shown in Fig. 2. The transient formed immediately after the flash of light shows absorption spectrum coincident with that of $\mathrm{CO}_{3}^{--}$(see grey lines in Fig. 2, obtained from experiments in the absence of insecticide). The half life of $2 \mathrm{~ms}$ observed for this transient is on the order expected for the reaction of $\mathrm{CO}_{3}^{-}$with $2 \times 10^{-4} \mathrm{M}$ IMD under the experimental conditions used. The transient formed after the decay of $\mathrm{CO}_{3}^{--}$shows an absorption maximum at 300-330 nm (full circles in Fig. 2) and is assigned to the organic transient formed after reaction (4).

An electron transfer reaction from aminic nitrogen to carbonate radical was proposed for aliphatic amines (Elango et al., 1985), anilines (Elango et al., 1984) and guanine (Shafirovih et al., 2001). Two different mechanisms were proposed for the attack of $\mathrm{CO}_{3}^{-}$radicals to aliphatic amines (Elango and coworkers). The electron transfer from the $\mathrm{N}$ atom to $\mathrm{CO}_{3}^{--}$yielding an amine radical cation followed by proton

Table 3 - Natural water abundance of reactive intermediates and corresponding reaction rate constants $k$ at $25{ }^{\circ} \mathrm{C}$ for IMD, THIA, and ACT.

\begin{tabular}{|c|c|c|c|c|}
\hline Reactive oxidant (RO) & $\mathrm{CO}_{3}^{--}$radicals & ${ }^{1} \mathrm{O}_{2}$ & DOM triplet & $\mathrm{HO}^{\bullet}$ radicals \\
\hline $\begin{array}{l}\text { Natural water abundance/M } \\
k_{(\mathrm{IMD}+\mathrm{RO})} / \mathrm{M}^{-1} \mathrm{~s}^{-1} \\
k_{(\mathrm{THIA}+\mathrm{RO})} / \mathrm{M}^{-1} \mathrm{~s}^{-1} \\
k_{(\mathrm{ACT}+\mathrm{RO})} / \mathrm{M}^{-1} \mathrm{~s}^{-1}\end{array}$ & $\begin{array}{l}10^{-13}-10^{-15 \mathrm{a}} \\
(4 \pm 1) \times 10^{6 \mathrm{e}} \\
(2.8 \pm 0.5) \times 10^{5 \mathrm{e}} \\
(1.5 \pm 1) \times 10^{5 \mathrm{e}}\end{array}$ & $\begin{array}{l}10^{-12}-10^{-13 b} \\
(5.5 \pm 0.5) \times 10^{6 f} \\
(3.9 \pm 1) \times 10^{7 f} \\
(3.6 \pm 1) \times 10^{7 f}\end{array}$ & $\begin{array}{l}10^{-13}-10^{-15} \mathrm{c} \\
(4.8 \pm 1) \times 10^{7} \mathrm{~g} \\
(1.5 \pm 1) \times 10^{8 \mathrm{~g}} \\
(3.6 \pm 1) \times 10^{7 \mathrm{~g}}\end{array}$ & $\begin{aligned} 10^{-17} & -10^{-15 \mathrm{~d}} \\
6 & \times 10^{10 \mathrm{~h}} \\
7.5 & \times 10^{10 \mathrm{~h}} \\
5.5 & \times 10^{10 \mathrm{~h}}\end{aligned}$ \\
\hline $\begin{array}{l}\text { a From Ref. Canonica et al. } \\
\text { b From Ref. Zepp et al. (1977 } \\
\text { c From Ref. Canonica et al. } \\
\text { d From Ref. Vione et al. ( } 200 \\
\text { e This work. } \\
\text { f From ref. Dell'Arciprete et } \\
\text { g From Ref. Dell'Arciprete et } \\
\text { h Taken from Ref. Dell'Arcip }\end{array}$ & er (1999). & & & \\
\hline
\end{tabular}




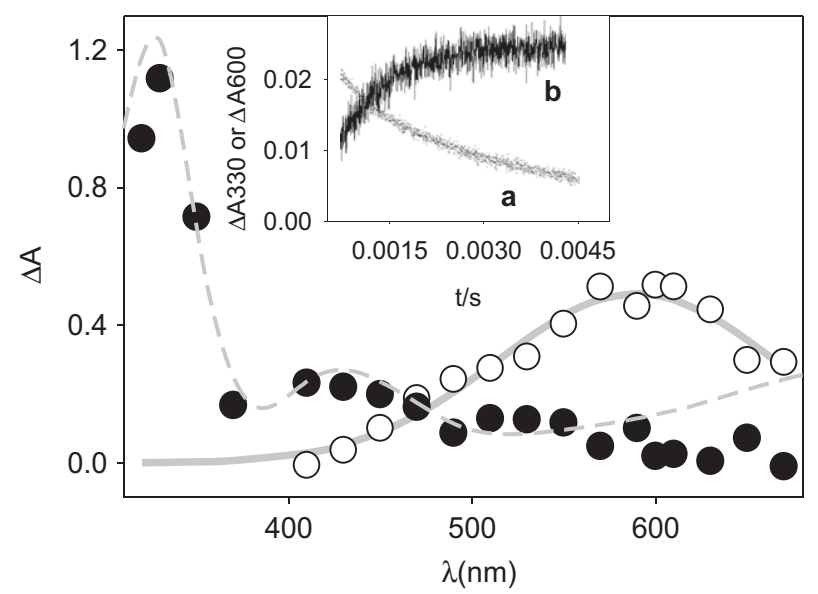

Fig. 2 - Transient spectra retrieved by a bilinear analysis of the absorption matrix obtained from flash photolysis experiments of air-saturated solutions containing $0.025 \mathrm{M}$ $\mathrm{S}_{2} \mathrm{O}_{8}^{2-} ; 1 \mathrm{M} \mathrm{HCO}_{3}^{-}$and $2 \times 10^{-4} \mathrm{M}$ IMD. The solid grey line stands for the spectrum of the $\mathrm{CO}_{3}^{-}$radical obtained in experiments under identical conditions but in the absence of the insecticide. The dashed-grey line stands for the $0.46 \times$ IMDRM $+0.54 \times$ IMDRH combination of the theoretical spectrum of IMDRM and IMDRH taken from Dell'Arciprete et al., 2011. Inset: Contribution of $\mathrm{CO}_{3}^{--}$ radical (curve $a$ ) and the organic transient formed after reaction (4) (curve b) to the absorbance of the traces at 600 and $330 \mathrm{~nm}$, respectively, for the experiments shown in the main figure.

elimination and $\alpha$-aminoalkyl radical formation seems to be the favoured mechanism for tertiary amines. For primary amines, a direct $\alpha$ - hydrogen abstraction to yield an $\alpha$-aminoalkyl radical seems to take place. Both mechanisms may be competitive in secondary amines. Considering that IMD has a tertiary amine group, the electron transfer mechanism might apply. The electron transfer Gibbs energy from insecticides to $\mathrm{CO}_{3}^{--}, \Delta_{\mathrm{ET}} \mathrm{G}^{0}$, can be calculated using Eq. (2).

$\Delta G_{\mathrm{ET}}^{0}=-\mathrm{F} \times\left[E^{0}\left(\mathrm{CO}_{3}^{\bullet-} / \mathrm{CO}_{3}^{2-}\right)-E^{0}\left(\mathrm{Ins}^{\bullet+} / \mathrm{Ins}\right)\right]$

Considering $\mathrm{E}^{\mathrm{O}}\left(\mathrm{Ins}^{+} / \mathrm{Ins}\right)<1.2 \mathrm{~V}$ for the reduction potentials of the chloronicotinoid insecticides (Dell'Arciprete et al., 2010) and $\mathrm{E}^{\mathrm{O}}\left(\mathrm{CO}_{3}^{-} / \mathrm{CO}_{3}^{2-}\right)=1.78 \mathrm{~V}$, the value $\Delta_{\mathrm{ET}} \mathrm{G}^{0}<-56 \mathrm{~kJ} / \mathrm{mol}$ is estimated. Consequently, the electron transfer reactions are thermodynamically allowed and the observed organic transient is suspected to be either an amine radical cation or an $\alpha$ aminoalkyl radical. Carbonate radical addition to the pyridine moiety of IMD is of minor significance as supported by the nature of the observed reaction products which maintain the pyridine ring even after prolonged irradiation.

To identify the organic radical formed after reaction (4), the transient spectrum is compared to those obtained by DFT calculations of the IMD radical cation (IMDRC) and $\alpha$-aminoalkyl radicals published in the literature (Dell'Arciprete et al., 2011). The theoretically obtained spectrum of IMDRC evidences an absorption maximum at $300 \mathrm{~nm}$ and a less intense band at $410 \mathrm{~nm}$. The $\alpha$-aminoalkyl radical in the heterocycle (IMDRH) presents an absorption maximum at
$310 \mathrm{~nm}$ and a shoulder at $450 \mathrm{~nm}$ while that of the $\alpha$-aminoalkyl radical at the methylene bridge (IMDRM) exhibits a maximum around $330 \mathrm{~nm}$. The sum of the spectrum of the two $\alpha$-aminoalkyl radicals in a 1:1.2 IMDRM: IMDRH ratio shows a good agreement with the organic radical of IMD (see dashed-grey line in Fig. 2), and is therefore assigned to these species.

\subsubsection{THIA and ACT radical intermediates}

Independent irradiation experiments performed with ACT and THIA show the formation of mainly one transient in the wavelength range from 400 to $750 \mathrm{~nm}$ with absorption maximum at $600 \mathrm{~nm}$, as shown in the figures in S.I.4 and S.I.5 for THIA and ACT, respectively. The transient spectrum is coincident with that of $\mathrm{CO}_{3}^{-}$and its $\sim 20 \mathrm{~ms}$ half life is on the order expected for the reaction of $\mathrm{CO}_{3}^{--}$with ACT or THIA under the experiment conditions. Therefore, the transient absorbing at $\lambda>400 \mathrm{~nm}$ is assigned to $\mathrm{CO}_{3}^{--}$radicals.

Due to the slow reaction between $\mathrm{CO}_{3}^{--}$and either ACT or THIA, it may be expected that the organic radical intermediates formed from these reactions are present in very low concentrations if their depletion rates are fast. In fact, considering an initial electron transfer from these insecticides to $\mathrm{CO}_{3}^{-}, \alpha$-aminoalkyl radicals from THIA and ACT are expected to be formed which are reported to decay in the ms time range (Dell'Arciprete et al., 2011). The resolution of the differential mass equations for an intermediate species involved in pseudo-first order consecutive reactions shown in Eq. (3), where IR stands for the $\alpha$-aminoalkyl radicals of either THIA or ACT and $k_{d}$ is the corresponding intermediate depletion rate constant, leads to Eq. (4). The subscript "o" indicates initial concentrations taken immediately after the flash of light.

$\mathrm{CO}_{3}^{--}+$Insecticide $($excess $) \stackrel{K_{4}}{\rightarrow}$ IR $\stackrel{K_{d}}{\rightarrow}$ Products

$[\mathrm{IR}]=\left[\mathrm{CO}_{3}^{-}\right]_{\circ} \frac{k_{4} \times[\mathrm{Ins}]}{k_{d}-k_{4} \times[\mathrm{Ins}]}\left[e^{-k_{4} \times[\mathrm{Ins}]}-e^{-k_{d}}\right]$

Under the conditions $k_{d}>k_{4} \times$ [Ins], the value of $k_{d}$ is reflected in the short rising portion of the intermediate concentration profile; at longer times, [IR] depletion is dominated by the exponential term $e^{-k_{4} \times[\text { [ns }]}$. In fact, the small absorbance traces obtained below $400 \mathrm{~nm}$ in experiments with THIA show $\sim 1 \mathrm{~ms}$ rise time and a $20 \mathrm{~ms}$ decay, in agreement with the previous discussion (see S.I.6). Traces obtained at $\lambda>400 \mathrm{~nm}$ due to $\mathrm{CO}_{3}^{--}$show rise times in the $\mu \mathrm{s}$ time range, within the duration of the flash of light. Therefore, the absorption traces obtained in the 350-400 nm wavelength range in experiments with THIA may be due to $\alpha$-aminoalkyl radicals, in coincidence with the reported absorption spectrum for these radicals (Dell'Arciprete et al., 2011).

\subsection{Reaction pathways}

Based on the detected intermediates and the observed reaction products, a pathway for the primary steps of the $\mathrm{CO}_{3}^{--}$ oxidation of IMD may be proposed, as shown in Scheme 2. An electron transfer pathway from IMD to $\mathrm{CO}_{3}^{\cdot-}$ yields $\mathrm{CO}_{3}^{2-}$ anions and the radical cation IMDRC (reaction path $a$ ). Further 


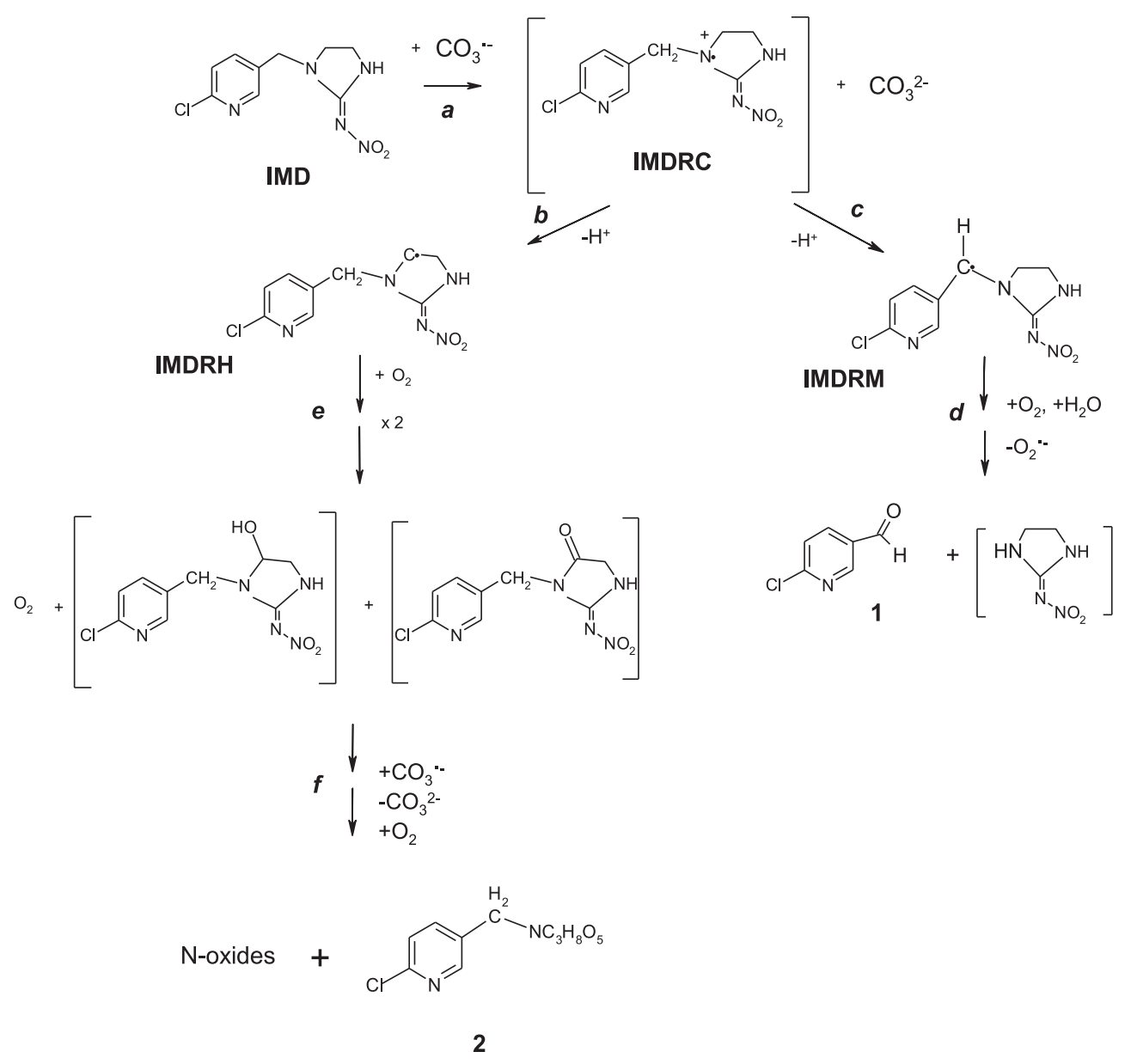

Scheme 2 - Reaction mechanism of IMD with carbonate radical. Transients and stable compounds in brackets are proposed, but not detected.

$\mathrm{H}^{+}$elimination from IMDRC leads to the $\alpha$-aminoalkyl radicals IMDRH, reaction path $b$, and IMDRM, reaction path $c$. The $\alpha$ aminoalkyl radicals are able to reduce $\mathrm{O}_{2}$ to superoxide (Baciocchi et al., 2004; Hiller and Asmus, 1983; Lalevée et al., 2007) and upon further addition of water cleave to yield 6chloronicotinaldehyde (reaction path $d$ ). Molecular oxygen addition to IMDRH and the further disproportionation of the resulting peroxyl radical yields the hydroxyl and the ketoderivative of IMD (reaction path $e$ ). The latter substances were not observed among the identified products; however, product 2 may only be formed from the sequential oxidation of these compounds by $\mathrm{CO}_{3}^{--}$, reaction path $f$.

Formation of THIA $\alpha$-aminoalkyl radicals and of products 1 and 2 in experiments with THIA may be explained by an initial electron transfer pathway as also suggested for IMD. Briefly, an initial electron transfer from the aminic N of THIA to $\mathrm{CO}_{3}^{--}$ yields the radical cation of the insecticide, THIARC and $\mathrm{CO}_{3}^{2-}$ anions (reaction path $g$ in Scheme 3). Further $\mathrm{H}^{+}$elimination at vicinal $C$ leads to the formation of $\alpha$-aminoalkyl radicals in the heterocycle ring, THIARH (reaction path $h$ ) and from the methylene bridge, THIARM (reaction pathway i). Reaction of THIARH with $\mathrm{O}_{2}$ and sequential oxidation initiated by $\mathrm{CO}_{3}^{--}$ leads to the formation of compound 2, reaction pathway $j$. THIARM addition of $\mathrm{O}_{2}$, elimination of superoxide and water addition leads to the formation of 6-chloronicotinaldehyde, reaction pathway $k$.

Formation of products 1 and 3 in experiments with ACT may also be explained by an initial electron transfer pathway from ACT to $\mathrm{CO}_{3}^{--}$yielding the radical cation ACTRC and $\mathrm{CO}_{3}^{2-}$ anions (reaction path $l$ in Scheme 4), as suggested for IMD and THIA. Further $\mathrm{H}^{+}$elimination leads to the formation of $\alpha$ aminoalkyl radicals in the methylene bridge, ACTRM (pathway $m$ ). ACTRM addition of $\mathrm{O}_{2}$ and water leads to the formation of 6-chloronicotinic aldehyde and the imine product 3 , reaction path $n$.

The computer simulations shown in Fig. 2 predict that only around $40 \%$ (30\%) of the formed primary products are due to the reaction of ACT (THIA) with $\mathrm{CO}_{3}^{--}$; the remaining percentage is due to the insecticides reaction with $\mathrm{SO}_{4}^{--}$radicals. The reported reaction pathway of $\mathrm{SO}_{4}^{-}$radical attack to the insecticides (Dell'Arciprete et al., 2011) is coincident with that proposed here for $\mathrm{CO}_{3}^{\circ}$; therefore, the same primary products are formed from reactions (4) and (5), as is the case of products 1 and 3 . Product 2 is formed from the primary products successive oxidation by $\mathrm{CO}_{3}^{-}$, as they were only observed in experiments in the presence of $\mathrm{CO}_{3}^{2-}$ anions. Therefore, Schemes 3 and 4 , also include $\mathrm{SO}_{4}^{--}$radical attack to THIA and ACT, reaction paths $g^{\prime \prime}$ and $l^{\prime \prime}$, respectively. 

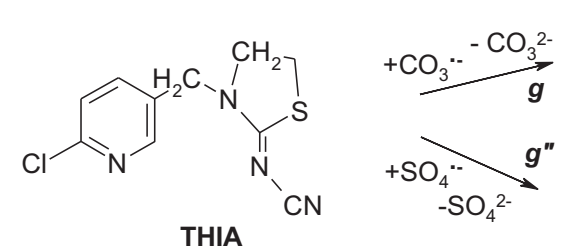<smiles>CN=C(SC)[N+](C)(C)Cc1ccc(Cl)nc1</smiles><smiles>N#CN=C1SCCN1Cc1ccc(Cl)nc1</smiles><smiles>[CH]CC</smiles>

THIARH

THIARM<smiles></smiles>

$\boldsymbol{k} \downarrow \begin{aligned} & +\mathrm{O}_{2},+\mathrm{H}_{2} \mathrm{O} \\ & -\mathrm{O}_{2}^{*}\end{aligned}$<smiles>[Mg]O[SbH3]</smiles>

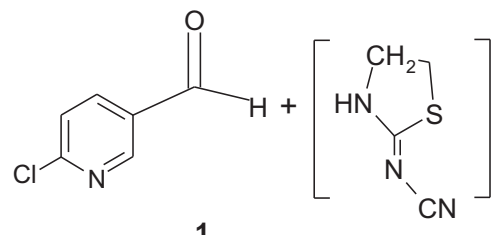

Scheme 3 - Mechanism for the reaction of THIA with carbonate radical anions. Sulphate radical attack to THIA is also shown. Transients and stable products in brackets are proposed, but not detected.<smiles>C/C(=N\C#N)N(C)Cc1ccc(Cl)nc1</smiles><smiles></smiles><smiles>CC(C)=NCc1ccc(Cl)nc1</smiles>

$$
m \mid-\mathrm{H}^{+}
$$<smiles>CC(=NN)N(C)Cc1ccc(Cl)nc1</smiles>

ACTRM

$$
n \mid \begin{aligned}
& +\mathrm{O}_{2} \\
& -\mathrm{O}_{2}{ }^{--},+2 \mathrm{H}_{2} \mathrm{O}
\end{aligned}
$$<smiles>CN/C(C)=N/C#N</smiles>

Scheme 4 - Proposed reaction mechanism for the reaction of ACT with carbonate radical anions. Sulphate radical attack to ACT is also shown. Transients and stable compounds in brackets are proposed, but not detected. 
Table 4 - Manifold of reactions depleting the neonicotinoid insecticides in natural waters. The corresponding rate constants at $25^{\circ} \mathrm{C}$ are shown in Table 3. $P_{i}$ stands for the organic radical of reaction $i$.
Insecticide $+\mathrm{CO}_{3}^{--} \rightarrow \mathrm{CO}_{3}^{2-}+\mathrm{P}_{4}$

Insecticide $+\mathrm{HO}^{\circ} \rightarrow \mathrm{OH}^{-}+\mathrm{P}_{9}$

Insecticide $+{ }^{1} \mathrm{O}_{2} \rightarrow \mathrm{P}_{10}$

Insecticide $+{ }^{3} \mathrm{DOM} \rightarrow \mathrm{P}_{11}$

\section{Discussion}

Submicromolar concentrations of the neonicotinoid insecticides reach the natural aqueous systems (Tennekes, 2010) where they may be degraded by biotic and abiotic pathways. Natural reservoirs show low concentrations of oxidizing radicals (see Table 3), such as hydroxyl $\left(\mathrm{HO}^{\circ}\right)$ and $\mathrm{CO}_{3}^{--}$radicals, singlet oxygen $\left({ }^{1} \mathrm{O}_{2}\right)$, and excited triplet states of dissolved organic matter, ${ }^{3} \mathrm{DOM}$, which are capable of initiating the oxidation of the pesticides. To evaluate the detoxifying capacity of natural water towards the different insecticides, a minimum reaction mechanism is considered which consists of the reactions of the insecticides with $\mathrm{CO}_{3}^{-}$and $\mathrm{HO}^{-}$radicals, ${ }^{1} \mathrm{O}_{2}$, and ${ }^{3} \mathrm{DOM}$, reactions (4), (9), (10) and (11), respectively, in Table 4. The absorption of $355 \mathrm{~nm}$ light by DOM produces ${ }^{3} \mathrm{DOM}$ of $160 \mathrm{~kJ} \mathrm{~mol}^{-1}$ energy (Bruccoleri et al., 1990, 1993), of the order of Rose Bengal triplet. Therefore, $k_{11}$ is assumed to be of the order of that reported for the reaction of the insecticides with Rose Bengal triplet (Dell'Arciprete et al., 2010). Table 3 shows the steady-state concentrations of reactive oxidants reported for natural waters, also containing dissolved $\mathrm{O}_{2}$, DOM, carbonates, etc. Scavenging of these oxidants by the

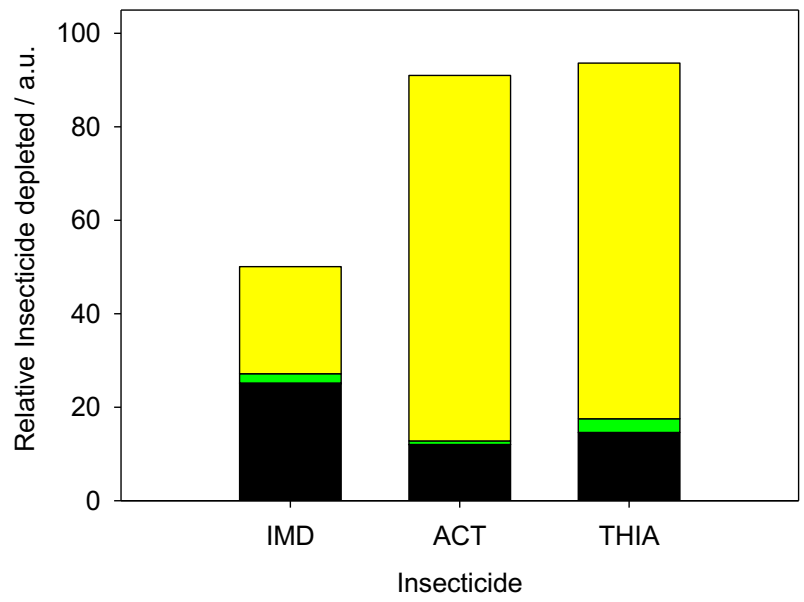

Fig. 3 - Expected IMD, THIA and ACT degradation after $16 \mathrm{hs}$ in "artificial natural water" containing $1 \times 10^{-8} \mathrm{M}$ initial concentrations of the insecticide, and steady-state concentrations $\left[\mathrm{HO}^{\circ}\right]_{\mathrm{ss}}=1 \times 10^{-16} \mathrm{M}$, $\left[{ }^{1} \mathrm{O}_{2}\right]_{\mathrm{ss}}=1 \times 10^{-12} \mathrm{M},\left[\mathrm{CO}_{3}^{--}\right]_{\mathrm{ss}}=\left[{ }^{3} \mathrm{DOM}\right]_{\mathrm{ss}}=1 \times 10^{-14} \mathrm{M}$. The consumption due to the different scavengers is depicted as: black: $\mathrm{HO}^{\circ}$, red: $\mathrm{CO}_{3}^{-}$(not visible in the scale), green: ${ }^{3} \mathrm{DOM}$ and yellow: ${ }^{1} \mathrm{O}_{2}$. (For interpretation of the references to colour in this figure legend, the reader is referred to the web version of this article.) natural water matrix components is already accounted for in the reported values. Therefore, the solution of the mass differential equations built for the latter set of reactions considering the steady-state concentrations of the reactive oxidants depicted in Table 3 yields information on the expected lifetime of the insecticides and on the amount of insecticide depleted due to the different reactive intermediates in natural waters. The obtained relations are shown in S.I.7.

An average half life $\left(t_{1 / 2}\right)$, as obtained from Eq. (5), of 16.0, 4.6 and 4.0 hs is expected for IMD, ACT, and THIA, respectively, under the experimental conditions of a "natural water" of the characteristics described before. Fig. 3 shows the predicted depletion of $1 \times 10^{-8} \mathrm{M}$ concentration of each of the insecticides after $16 \mathrm{~h}$ in the "natural water". Singlet molecular oxygen is the most effective species degrading the insecticides, as it is able to degrade $46 \%$ IMD, $81 \%$ THIA, and $86 \%$ ACT. Despite $\mathrm{HO}^{\bullet}$ radicals show the smallest steady-state concentration, they are responsible for the depletion of almost 49\% IMD, 16\% THIA, and 13\% ACT. Despite its higher concentration, carbonate radicals is the least effective oxidant in depleting the insecticides.

$$
\begin{aligned}
\mathrm{t}_{1 / 2}= & \ln 2 /\left(k\left(\mathrm{CO}_{3}^{\bullet-}+\mathrm{Ins}\right) \times\left[\mathrm{CO}_{3}^{\bullet-}\right]_{\mathrm{ss}}+k\left({ }^{1} \mathrm{O}_{2}+\mathrm{Ins}\right) \times\left[{ }^{1} \mathrm{O}_{2}\right]_{\mathrm{ss}}\right. \\
& \left.+k\left(\mathrm{HO}^{\cdot}+\mathrm{Ins}\right) \times\left[\mathrm{HO}^{\circ}\right]_{\mathrm{ss}}+k\left({ }^{3} \mathrm{DOM}+\mathrm{Ins}\right) \times\left[{ }^{3} \mathrm{DOM}\right]_{\mathrm{ss}}\right)
\end{aligned}
$$

\section{Conclusions}

The insecticides IMD, THIA, and ACT chemically react with $\mathrm{CO}_{3}^{--}$radical anions with rate constants of $(4 \pm 1) \times 10^{6}$, $(2.8 \pm 0.5) \times 10^{5}$, and $(1.5 \pm 1) \times 10^{5} \mathrm{M}^{-1} \mathrm{~s}^{-1}$, respectively. The amidine nitrogen of the molecule is the preferred site of attack of the insecticides, as also observed for $\mathrm{SO}_{4}^{--}$radical, singlet oxygen, and the triplet state of Rose Bengal (Dell'Arciprete et al., 2009, 2010, 2011).

The low reactivity observed for $\mathrm{CO}_{3}^{--}$compared to $\mathrm{HO}^{\bullet}$ radicals and ${ }^{1} \mathrm{O}_{2}$ indicates that it is little effective in depleting neonicotinoid insecticides. It would take around 6.6 months and 7.4 years to degrade IMD and ACT, respectively, in natural waters containing only $\mathrm{CO}_{3}^{-}$radicals as scavengers.

Adequate Advanced Oxidation Processes (AOP) for treatment of water and wastewaters contaminated with IMD, ACT, and THIA should be based on the generation of either $\mathrm{HO}^{\bullet}$ or $\mathrm{SO}_{4}^{-}$radicals as the main oxidizing species. The presence of $\mathrm{CO}_{3}^{2-} / \mathrm{HCO}_{3}^{-}$anions in the water matrix will considerably diminish the efficiency of the process.

\section{Acknowledgements}

This research was financially supported by Consejo Nacional de Investigaciones Científicas y Técnicas (CONICET), Agencia Nacional de Promoción Científica y Tecnológica (Argentina, project PICT 2007 number 00308), and Agencia Española de Cooperación Internacional (project A/8199/07). M.L.D. thanks CONICET for a graduate studentship. M.C.G. is a research member of CONICET. D.O.M. is a research member of 
Comisión de Investigaciones Científicas de la Provincia de Buenos Aires (CIC), Argentina. L.S.J. acknowledges Ministerio de Ciencia e Innovación for his Juan de la Cierva scholarship.

\section{Appendix A. Supplementary material}

Supplementary data related to this article can be found online at doi:10.1016/j.watres.2012.03.051.

\section{R E F E R E N C E S}

Alegre, M.L., Geronés, M., Rosso, J.A., Bertolotti, S.G., Braun, A.M., Mártire, D.O., Gonzalez, M.C., 2000. Kinetic study of the reactions of chlorine atoms and $\mathrm{Cl}_{2}^{--}$radical anions in aqueous solutions. 1. Reaction with benzene. Journal Physical Chemistry A 104 (14), 3117-3125.

Baciocchi, E., Del Giacco, T., Lapi, A., 2004. Oxygenation of benzyldimethylamine by singlet oxygen. Products and mechanism. Organic Letters 6, 4791-4794.

Behar, D., Czapski, G., Duchovny, I., 1970. Carbonate radical in flash photolysis and pulse radiolysis of aqueous carbonate solutions. Journal of Physical Chemistry 74 (10), 2206-2210.

Badriyha, B.N., Ravindran, V., Den, W., Pirbazari, M., 2003. Bioadsorber efficiency, design, and performance forecasting for alachlor removal. Water Research 37 (17), 4051-4072.

Bensasson, R.V., Land, E.J., Truscott, T.G., 1983. Flash Photolysis and Pulse Radiolysis: Contributions to the Chemistry of Biology and Medicine. Pergamon, New York.

Bruccoleri, A., Langford, C.H., Arbour, C., 1990. Pulsed photo acoustic evaluation of intersystem crossing quantum yields in fulvic acid. Environmental Technology Letters 11 (2), 169-172.

Bruccoleri, A., Pant, B., Sharma, D.K.,H., Langford, C., 1993. Evaluation of primary photoproduct quantum yields in fulvic acids. Environmental Science and Technology 27 (5), 889-894.

Busset, C., Mazellier, P., Sarakha, M., De Laat, J., 2007. Photochemical generation of carbonate radicals and their reactivity with phenol. Journal of Photochemistry and Photobiology A 185 (2), 127-132.

Canonica, S., Jans, U., Stemmler, K., Hoigne, J., 1995. Transformation kinetics of phenols in water: photosensitization by dissolved natural organic material and aromatic ketones. Environmental Science and Technology 29 (7), 1822-1831.

Canonica, S., Kohn, T., Mac, M., Real, F.J., Wirz, J., von Gunten, U., 2005. Photosensitizer method to determine rate constants for the reaction of carbonate radical with organic compounds. Environmental Science and Technology 39 (23), 9182-9188.

Cernigoj, U., Stanga, U.L., Trebse, P., 2007. Degradation of neonicotinoid insecticides by different advanced oxidation processes and studying the effect of ozone on $\mathrm{TiO}_{2}$ photocatalysis. Applied Catalysis B 75 (3), 229-238.

Clifton, C.L., Huie, R.E., 1993. Rate constants for some hydrogen abstraction reactions of the carbonate radical. International Journal of Chemical Kinetics 25 (3), 199-204.

Criquet, J., Karpel Vel Leitner, N., 2009. Degradation of acetic acid with sulfate radical generated by persulfate ions photolysis. Chemosphere 77 (2), 194-200.

Czapski, G., Holcman, J., Bielski, B.H.J., 1994. Reactivity of nitric oxide with simple short-lived radicals in aqueous solutions. Journal of American Chemical Society 116 (25), 11465-11469.

Dell'Arciprete, M.L., Santos-Juanes, L., Arques Sanz, A., Vicente, R., Amat, A.M., Furlong, J.P., Mártire, D.O.,
Gonzalez, M.C., 2009. Reactivity of hydroxyl radicals with neonicotinoid insecticides: mechanism and changes in toxicity. Photochemistry and Photobiology Sciences 8 (7), 1016-1023.

Dell'Arciprete, M.L., Santos-Juanes, L., Arques, A., Vercher, R.F., Amat, A.M., Furlong, J.P., Mártire, D.O., Gonzalez, M.C., 2010. Reactivity of neonicotinoids pesticides with singlet oxygen. Catalysis Today 151 (1), 137-142.

Dell'Arciprete, M.L., Cobos, C.J., Mártire, D.O., Furlong, J.P., Gonzalez, M.C., 2011. Reaction kinetics and mechanisms of neonicotinoid pesticides with sulphate radicals. New Journal of Chemistry 35 (3), 672-680.

Elango, T.P., Ramakrishnan, V., Vancheesan, S., Kuriacose, J.C., 1985. Reaction of the carbonate radical with aliphatic amines. Tetrahedron 41 (18), 3837-3843.

Elango, T.P., Ramakrishnan, V., Vancheesan, S., Kuriacose, J.C., 1984. Reaction of the carbonate radical with substituted anilines. Proceedings of the Indian National Science Academy (Chem. Sci.) 93 (1), 47-52.

Gear, C.W., 1971. Numerical Initial Value Problems in Ordinary Differential Equations. Prentice Hall, Englewood Cliffs, New Jersey.

Haygarth, K.S., Marin, T.W., Janik, I., Kanjana, K., Stanisky, C.M., Bartels, D.M., 2010. Carbonate radical formation in radiolysis of sodium carbonate and bicarbonate solutions up to $250{ }^{\circ} \mathrm{C}$ and the mechanism of its second order decay. Journal of Physical Chemistry A 114 (5), 2142-2150.

Herrmann, H., Reese, A., Zelhrer, R., 1995. Time-resolved UV/VIS diode array radical anions in aqueous solution absorption spectroscopy of $\mathrm{SO}_{\mathrm{x}}^{-}(\mathrm{x}=3,4,5)$. Journal of Molecular Structure 348, 183-186.

Hiller, K.O., Asmus, K.D., 1983. Formation and reduction reactions of $\alpha$-amino radicals derived from methionine and its derivatives in aqueous solutions. Journal of Physical. Chemistry 87 (19), 3682-3688.

Huang, J., Mabury, S.A., 2000a. A new method for measuring carbonate radical reactivity toward pesticides. Environmental Toxicology and Chemistry 19 (6), 1501-1507.

Huang, J., Mabury, S.A., 2000b. The role of carbonate radical in limiting the persistence of sulfur-containing chemicals in sunlit natural waters. Chemosphere 41 (11), 1775-1782.

Huie, R.E., Clifton, C.L., Neta, P., 1991. Electron transfer reaction rates and equilibria of the carbonate and sulfate radical anions. Radiation Physics and Chemistry 38 (5), $477-481$.

Lalevée, J., Graff, B., Allonas, X., Fouassier, J.P., 2007. Aminoalkyl radicals: direct observation and reactivity toward oxygen, 2,2,6,6-Tetramethylpiperidine- $\mathrm{N}$-oxyl, and methyl acrylate. Journal of Physical Chemistry A 111 (30), 6991-6998.

Lam, M.L., Tantuco, K., Mabury, S.A., 2003. Photofate: a new approach in accounting for the contribution of indirect photolysis of pesticides and pharmaceuticals in surface water. Environmental Science and Technology 37 (5), 899-907.

Lower, S.K., 1999. Carbonate equilibria in natural waters. Available on the web at: http://www.chem1.com/acad/ webtext/pdf/c3carb.pdf (October 2011).

Malato, S., Caceres, J., Aguera, A., Mezcua, M., Hernendo, D., Vial, J., Fernandez-Alba, R., 2001. Degradation of imidacloprid in water by photo-Fenton and $\mathrm{TiO}_{2}$ photocatalysis at a solar pilot plant: a comparative study. Environmental Science and Technology 35 (21), 4359-4365.

Mazellier, P., Leroy, E., De Laat, J., Legube, B., 2002. Tranformation of carbendazim induced by the $\mathrm{H}_{2} \mathrm{O}_{2} / \mathrm{UV}$ system in the presence of hydrogenocarbonate ions: involvement of the carbonate radical. New Journal of Chemistry 26 (12), 1784-1790. 
Mazellier, P., Busset, C., Delmont, A., De Laat, J., 2007. A comparison of fenuron degradation by hydroxyl and carbonate radicals in aqueous solution. Water Research 41 (20), 4585-4594.

McElroy, W.J., 1990. Laser photolysis study of the reaction of $\mathrm{SO}_{4}^{--}$ with $\mathrm{Cl}^{-}$and the subsequent decay of $\mathrm{Cl}_{2}^{--}$in aqueous solutions. Journal of Physical Chemistry 94 (6), 2435-2441.

Moza, P.N., Hustert, K., Feicht, E., Kettrup, A., 1998. Photolysis of imidacloprid in aqueous solution. Chemosphere 36 (3), 497-502.

Neta, P., Huie, R.E., Ross, A.B., 1988. Rate constants for reactions of inorganic radicals in aqueous solution. Journal of Physical Chemistry Reference Data 17 (3), 1027-1229.

Padmaja, S., Neta, P., Huie, R.E., 1993. Rate constants for some reactions of inorganic radicals with inorganic ions. Temperature and solvent dependence. International Journal of Chemical Kinetics 25 (6), 445-455.

Redlich, D., Shahin, N., Ekici, P., Friess, A., Parlar, H., 2007. Kinetical study of the photoinduced degradation of imidacloprid in aquatic media. Clean 35 (5), 452-458.

Ross, A.B., Mallard, W.G., Helman, W.P., Buxton, G.V., Huie, R.E., Neta, P., 1998. NDRL-NIST Solution Kinetics Database, 1998: Ver. 3.0×, Notre Dame Radiation Laboratory, Notre Dame. Available on the web at:. IN and National Institute of Standards and Technology, Gaithersburg, MD http://kinetics. nist.gov/solution/ (March 2008).

San Román, E.A., Gonzalez, M.C., 1989. Analysis of spectrally resolved kinetic data and time-resolved spectra by bilinear regression. Journal of Physical Chemistry 93 (9), 3532-3536.

Shafirovih, V., Dourandin, A., Huang, W., Geacintov, N.E., 2001. The carbonate radical is a site-selective oxidizing agent of guanine in double-stranted oligonucleotides. The Journal of Biological Chemistry 276 (27), 24621-24626.

Tennekes, H.A., Sánchez-Bayo, F., 2011. Time-dependent toxicity of neonicotinoids and other toxicants: implications for a new approach to risk assessment. Journal of Environment and Analytical Toxicology. S:4-001.

Tennekes, H.A., 2010 In http://www.boerenlandvogels.nl/de/ content/contamination-dutch-surface-water-imidaclopridthreatens-insects.

Vione, D., Falletti, G., Maurino, V., Minero, C., Pelizzetti, E., Malandrino, M., Ajassa, R., Olariu, R., Arsene, C., 2006. Sources and sinks of hydroxyl radicals upon irradiation of natural water samples. Environmental Science and Technology 40 (12), 3775-3781.

Vione, D., Maurino, V., Minero, C., Carlotti, M.E., Chiron, S., Barbati, S., 2009a. Modelling the occurrence and reactivity of the carbonate radical in surface freshwater. Comptes Rendus Chimie 12 (8), 865-871.

Vione, D., Khanra, S., Man, S., Maddigapu, P., Das, R., Arsene, C., Olariu, R., Maurino, V., Minero, C., 2009b. Inhibition vs. enhancement of the nitrate-induced phototransformation of organic substrates by the $\bullet \mathrm{OH}$ scavengers bicarbonate and carbonate. Water Research 43 (18), 4718-4728.

Wamhoff, H., Schneider, V., 1999. Photodegradation of imidacloprid. Journal of Agricultural and Food Chemistry 47 (4), 1730-1734.

Wu, C.l., Linden, K.G., 2010. Phototransformation of selected organophosphorus pesticides: roles of hydroxyl and carbonate radicals. Water Research 44 (12), 3585-3594.

Zabar, R., Dolec, D., Jerman, T., Franko, M., Trebse, P., 2011. Photolytic and photocatalytic degradation of 6-chloronicotinic acid. Chemosphere. doi:10.1016/j.chemosphere.2011.06.107.

Zepp, R.G., Wolfe, N.L., Baughman, G.L., Hollis, R.C., 1977. Singlet oxygen in natural waters. Nature 267 (5610), 421-423.

Zuo, Z., Cai, Z., Katsumura, Y., Chitose, N., Muroya, Y., 1999. Reinvestigation of the acid-base equilibrium of the (bi) carbonate radical and $\mathrm{pH}$ dependence of its reactivity with inorganic reactants. Radiation Physics and Chemistry 55 (1), 15-23. 